\title{
Antiretroviral therapy (ART) adherence and correlates to non-adherence among people on ART in Estonia
}

\author{
Anneli Uuskula ${ }^{1}$, Kaja-Triin Laisaar ${ }^{1 *}$, Mait Raag ${ }^{1}$, K Rivet Amico ${ }^{2}$, Anjali Sharma ${ }^{3}$, Jack DeHovitz ${ }^{3}$ \\ From 17th International Symposium on HIV and Emerging Infectious Diseases (ISHEID) \\ Marseille, France. 23-25 May 2012
}

\section{Introduction}

There is limited data on antiretroviral therapy (ART) adherence among patients in Eastern Europe, despite the high incidence of HIV infection and the growing number of HIV-infected individuals who are being prescribed ART. We conducted a study to measure rates of adherence to ART and factors associated with nonadherence among patients receiving care at an outpatient HIV clinic in Estonia.

\section{Materials and methods}

The study was based on cross-sectional data from a convenience sample of 161 patients receiving outpatient HIV care. Data were obtained via interviewer administered surveys and data abstraction from clinical records. Adherence was measured from 3-day patient self-report.

\section{Results}

Among the 161 participants (mean age 33 and 55\% male / $45 \%$ female), two thirds (64\%) had been infected with HIV through intravenous drug use. Most (74\%) were coinfected with hepatitis C (HCV). Perfect adherence over the last 3-days was commonly reported [87\% (95\% CI 80 $92 \%)]$, with non-perfect adherence associated with greater concerns about the potential negative consequences of taking ART [AOR 5.8 (95\% CI 1.3 - 45.7)] and fewer antiretroviral medications (ARVs) in one's current regimen (2 or fewer different ARVs vs 3 or more different ARVs: AOR 17.0 (95\% CI 3.7 - 97.6).

\section{Conclusions}

Self-reported ART adherence in this sample of Estonian HIV-infected patients in clinical care was similar to rates observed in Western Europe and other developed countries. The results suggest that adherence education and support could be most beneficial, if specifically targeting the development of positive beliefs, reduction of negative expectations towards ART and when helping patients manage negative treatment experience, particularly with regimens including multiple ARVs.

\section{Author details}

${ }^{1}$ Department of Public Health, University of Tartu, Tartu, Estonia. ${ }^{2}$ Center for Health Intervention and Prevention, University of Connecticut, Storrs, CT, USA. ${ }^{3}$ Division of Infectious Diseases, State University of New York Downstate Medical Center, Brooklyn, NY USA.

Published: 25 May 2012

$$
\begin{aligned}
& \text { doi:10.1186/1742-4690-9-S1-P80 } \\
& \text { Cite this article as: Uuskula et al.: Antiretroviral therapy (ART) adherence } \\
& \text { and correlates to non-adherence among people on ART in Estonia. } \\
& \text { Retrovirology } 20129 \text { (Suppl 1):P80. } \\
& \text { Submit your next manuscript to BioMed Central } \\
& \text { and take full advantage of: } \\
& \text { - Convenient online submission } \\
& \text { - Thorough peer review } \\
& \text { - No space constraints or color figure charges } \\
& \text { - Immediate publication on acceptance } \\
& \text { - Inclusion in PubMed, CAS, Scopus and Google Scholar } \\
& \text { - Research which is freely available for redistribution } \\
& \text { Submit your manuscript at } \\
& \text { www.biomedcentral.com/submit }
\end{aligned}
$$

\footnotetext{
* Correspondence: kaja-triin.laisaar@ut.ee
Department of Public Health, University of Tartu, Tartu, Estonia

Full list of author information is available at the end of the article
} 